\title{
Indicators of distress in newly diagnosed breast cancer patients
}

Andrea Chirico, Fabio Lucidi, Luca Mallia, Massimiliano D'Aiuto, Thomas Merluzzi

Background: The diagnosis, treatment, and long-term management of cancer can present individuals with a multitude of stressors at various points in that trajectory. Psychosocial distress may appear early in the diagnostic process and have negative effects on compliance with treatment and subsequent quality of life. Purpose: The aim of the study was to determine early-phase predictors of distress before any medical treatment. Method: Consistent with the goals of the study, 123 newly diagnosed breast cancer patients (20 to 74 years old) completed multiple indicators of knowledge about breast cancer management and treatment, attitudes toward cancer, social support, coping efficacy, and distress. Results: SEM analysis confirmed the hypothesized model. Age was negatively associated with the patient's knowledge $(\beta=-0.22)$, which, in turn, was positively associated with both attitudes toward breast cancer $(\beta=0.39)$ and coping self-efficacy ( $\beta$ $=0.36)$. Self-efficacy was then directly related to psychological distress $(\beta=-0.68)$. Conclusions: These findings establish indicators of distress in patients early in the cancer trajectory. From a practical perspective, our results have implications for screening for distress and for the development of early interventions that may be followed by healthcare professionals to reduce psychological distress. 


\section{Andrea Chirico}

5 National Cancer Institute Fondazione "G.Pascale" Naples and "Sapienza" University of Rome

6 Fabio Lucidi

7 "Sapienza" University of Rome

\section{Luca Mallia}

9 University of Rome "Foro Italico" and "Sapienza" University of Rome

10 Massimiliano D'Aiuto

11 National Cancer Institute Fondazione "G.Pascale", Naples

\section{Thomas V. Merluzzi}

13 University of Notre Dame

Andrea Chirico, Breast Cancer Department, National Cancer Institute Fondazione

"G.Pascale", Naples, Europe, Italy, and Department of Psychology of Developmental and

17 Socialisation Processes, "Sapienza" University of Rome, Rome, Europe, Italy, Fabio Lucidi,

19 of Rome, Rome, Europe, Italy, Luca Mallia, Department of Movement, Human and Health

20 Sciences, University of Rome "Foro Italico", Rome, Europe, Italy and Department of

21 Psychology of Developmental and Socialisation Processes, "Sapienza" University of Rome,

22 Rome, Europe, Italy, Massimiliano D’Aiuto Breast Cancer Department, National Cancer

23 Institute Fondazione "G.Pascale", Naples, Europe, Italy, and Thomas V. Merluzzi Department of

24 Psychology, University of Notre Dame, Notre Dame,USA. 

Correspondence concerning this article should be addressed to Andrea Chirico, email: andrea.chirico@uniroma1.it or dr.andreachirico@gmail.com

\section{Introduction}

31 the most prevalent type accounting for $17.1 \%$ of all cancer deaths in women each year. In all

32 phases of the cancer trajectory, from diagnosis and treatment to long-term management, patients

33 may experience financial strains, difficulty in interpersonal relationships, physical symptoms,

34 and emotional distress (Philip et al., 2013). The prevalence of psychological distress among

35 breast cancer patients is higher than the general population, which increases the risk for

36 developing clinical levels of anxiety and depression (Burgess et al., 2005; Deshields et al., 2006;

37 Mehnert \& Koch 2008; Vahdaninia et al., 2010; Montgomery et al., 2010, Hill et al., 2011) that

38 can adversely affect treatment compliance.

Whereas there is a great deal of literature on distress during the course of treatment

40 (Lepore \& Coyne, 2006), less is known about the time between diagnosis and the beginning of

41 treatment. Although, research demonstrates that moderate to high levels of psychosocial distress

42 appear early on in the cancer diagnosis process (e.g., Nosarti et al., 2001; Lauzier et al., 2010;

43 Andreu et al., 2012; Costa-Requena et al., 2013), it is important to also determine the

44 demographic, social, and psychological variables that mitigate or lessen that initial distress,

45 which then might set the course for coping with the disease and its treatments.

46 The current study focuses on the time after diagnosis, before treatment, and is imbedded

47 in the biobehavioral model of cancer stress and disease course (Andersen et al., 1994). Based on 
48 the biobehavioral model and the self-regulation processes in which people engage (Carver \&

49 Scheier, 1998), the early stages of the cancer trajectory may be critical in setting the course for

50 reducing risk for clinical distress (Lam et al., 2012). In fact, the literature is rather clear on the

51 relationship between distress and a number of issues that impinge upon engagement in treatment,

52 recovery from illness, satisfaction with the provision of health care services (Costanzo et al.,

53 2007; Manning \& Bettencourt, 2011) and adjusting to life after treatment (Burgess et al., 2005;

54 Fiszer et al., 2014). Congruent with this model several studies have revealed that a high level of

55 preoperative or immediate postoperative distress (Nosarti et al., 2001; Gallagher et al., 2002;

56 Badger et al., 2004; Lam et al., 2007; Millar et al., 2005; Lam et al., 2012) resulted in poorer

57 psychological outcomes in the subsequent treatment period than low levels of distress. Moreover,

58 psychological distress had a negative effect on patients' quality of life, and, as noted earlier, on

59 compliance with treatment (Ayres et al., 1994; Colleoni et al., 2000; Bui et al., 2005; Reich et al.,

60 2008; Manning \& Bettencourt 2011; Costa-Requena et al., 2013; Philip et al., 2013). Patients

61 who are less anxious and depressed as they enter the treatment course of their cancer show a

62 better adjustment to illness, request lower levels of medical attention and create lower medical

63 costs than patients with higher levels of anxiety and depression (e.g., Butler et al., 2006).

64 Thus, early intervention may be the key to mitigating distress (Casellas-Grau et al., 2014),

65 however, a first step in that process would be to identify critical demographic, social, and

66 psychological predictors of distress that may be the focus of that intervention.

67 As regards demographic variables, generally studies have not supported any relationship

68 between patients' marital status or education and psychological distress (Avis, et al., 2005; Reich

69 et al., 2008; Vahdaninia et al., 2010; Mertz et al., 2012), but do report significant age differences

70 in patients' psychological distress with younger age related to greater distress and poorer 
71 psychological adjustment following diagnosis compared to older age (van't Spijker et al., 1997;

72 Avis et al., 2012; Mertz et al., 2012). Yet, the effects of age are not uniformly related to distress

73 (Maunsell et al., 1992; Philip et al., 2013). Despite these differences in findings, a

74 comprehensive analysis of age and adjustment to cancer (Mosher \& Danoff-Burg 2005) stressed

75 the importance of focusing on the relationship between age and patients' psychological distress

76 and strongly recommended analyzing mediators of this relationship. Also, there is little known

77 about age effects early on in the cancer trajectory.

Several studies and reviews focused their attention on social support in cancer patients in treatment (Grassi et al., 1993; Merluzzi \& Sanchez 1997; Merluzzi et al., 2001; Friedman et al., 2006; Arora et al., 2007; Nausheen et al., 2009; Henselmans et al., 2010; Heitzmann et al., 2011;

81 Philip et al., 2013). Perceived social support (i.e., from family, friends and significant others) has

82 been established as protective factor, which mitigates psychological distress in breast cancer 83 patients (Friedman et al., 2006) and specifically in newly diagnosed patients (Arora et al. 2007;

84 Drageset et al., 2012), and, therefore, is included in the model in the current study.

There is also evidence that coping mitigates or exacerbates distress over time in cancer

86 patients by engaging several mechanisms. For example, disengagement and denial coping tend

87 to undo the positive effects of optimism on distress in a mediated model of adjustment to breast

88 cancer (Carver et al., 1993). Also, in a longitudinal model, emotionally expressive coping in

89 breast cancer patients was associated with an increase in physical health and reductions in

90 distress (Stanton et al., 2000). Along those lines, self-efficacy for coping, that is expectations

91 about the ability to cope with cancer, plays a critical role in influencing cancer-related outcomes

92 including distress. There is a negative relationship between perceived self-efficacy for coping

93 with cancer and psychological distress in cancer patients (Merluzzi \& Sanchez 1997: Merluzzi et 
94 al. 2001; Howsepian \& Merluzzi 2009: Heitzmann et al. 2011: Philip et al. 2013) and,

95 specifically, in breast cancer patients (Henselmans et al. 2010). Interestingly, self-efficacy for

96 coping represents how the patient might expect to cope with cancer, and can be assessed even if

97 the patient is not yet in treatment. Thus, it is a very relevant variable to assess for those newly

98 diagnosed.

99 According to social cognitive theory (Bandura 1997), self-efficacy is influenced by the

100 personal knowledge and prior experiences (Avci, 2008; Heitzmann et al., 2011). Accordingly,

101 several studies have established that women's personal knowledge about breast cancer, including

102 its management and medical treatment, is inversely related to their psychological distress (Ohaeri

103 et al., 2012), compliance with preventative behaviors such as mammography (Holt et al., 2003b),

104 and time orientation regarding the consequences of breast cancer (Lukwago et al., 2003). Thus,

105 with regard to the proposed model, and consistent with Self-Efficacy Theory, coping self-

106 efficacy would be expected to mediate the relationship between knowledge and psychological

107 distress.

108 Though not as extensively studied as knowledge and coping efficacy, patients' attitudes

109 towards cancer may be a precursor to coping. Most of the research on attitudes is in the context

110 of health care providers' (Johnson et al., 2013) or people's attitudes (Schernhammer et al., 2010)

111 toward prevention and screening. However, one study has shown that compared to positive

112 attitudes, negative attitudes toward breast cancer and its treatment were associated with a higher

113 level of psychological distress (Gilbar, 2003).

114 In sum, in order to understand what might prevent distress early in the cancer trajectory,

115 studies need to be conducted on the time between diagnosis and the beginning of treatment in

116 which relevant variables are investigated in terms of their role in mitigating or exacerbating 
117 distress. Among those there is support for including age, knowledge, attitudes, social support and

118 self-efficacy expectations for coping. In a cross-sectional design we tested a model in which we

119 hypothesized that age is related to patient's knowledge about breast cancer, which in turn, is

120 related to both attitudes toward breast-cancer treatment and coping self-efficacy. We further

121 hypothesized that these latter two variables would directly related to the level of patients'

122 psychological distress, and mediate the effects of knowledge. The independent contribution of

123 social support was also evaluated (Fig. 1).

\section{Materials \& Method}

\section{Participants}

126 This study was conducted at the Breast Oncology Department of the National Cancer

127 Institute 'Giovanni Pascale' Foundation in Naples, Italy. Medical consultants identified 130

128 newly diagnosed breast cancer patients during the period from January to April 2010. All

129 patients were recruited during their hospitalization. These patients were admitted to hospital for

130 examination and were then scheduled for surgery within 1-3 days. At the time of admission, the

131 specific type of surgery that would be performed (e.g., Lumpectomy, Quadrantectomy, or

132 Mastectomy) had not been determined. Also none of these patients had previously received

133 adjuvant chemotherapy or any other cancer treatments (i.e., surgery or radiotherapy).

134 Demographic information, staging data, and familial history of breast cancer were collected from 135 medical records after obtaining informed consent and are contained in Table 1 . All patients $(N=$

136 130) consented to be interviewed for the study; however, seven did not answer all the interview

137 questions and were excluded from the analysis. In the final sample, age ranged from 20 to 74

138 years $(M$ age $=45.69 ; S D=10.01)$.

\section{Procedures}


All the patients were approached by a psychologist who described the research project

141 and presented the consent form. After giving consent they participated in a structured face-to-

142 face interview lasting about 30 minutes administered by the first author (a psychologist trained in

143 conducting diagnostic interviews).

\section{Measures}

The interviews were based on the administration of the following measures.

mammography, breast cancer, and breast cancer treatment was evaluated through scales

148 successfully used in previous studies in prevention settings (Holt et al., 2003a; Holt et al., 2003b)

knowledge: five items assessed perceptions of what mammograms can accomplish. For example,

one item asked whether participants thought that having a mammogram could reduce their risk of

152 dying from breast cancer. (2) Breast cancer knowledge: five items assessed knowledge about

153 breast cancer. For example, one item assessed whether the participant knew if most lumps turn

154 out to be breast cancer. (3) Breast cancer treatment knowledge: three items assessed knowledge

155 about breast cancer treatment. For example, one item asked whether the participant knew if

156 breast cancer had a good chance of being cured if it is detected early. Response options were yes,

157 no, and not sure and correct answers were assigned 1 point, while incorrect and "don't know"

158 answers were scored as 0 . The total score was the mean of the scale scores. In Holt et al., (2003a)

159 test-retest reliability for this scale was acceptable, ranging from: $\mathrm{r}=.45-.68, \mathrm{p}<.01$. The

160 distributions of the scale scores and the total point score were acceptable with no skewness and

161 kurtosis problems. The original scale was provided directly by the authors, and the translated

162 measure used in the present study is available upon request. 

were measured by asking patients to express the extent to which they thought that "regularly

165 following breast cancer treatment regimens would be..." fundamental, unpleasant, useless, 166 worrying, right, and reassuring. Each item ranged on a 5-point scale, from 1 (not at all) to 5

167 (completely). The three negatively keyed items were "reverse-scored". The measure was

168 developed by the authors, following the recommendations of Ajzen (1991) for attitude measure

169 development. The face validity of the scale as well as the clarity of the items, were preliminarily

170 evaluated through a think-aloud procedure ${ }^{1}$ in a sample of 25 volunteer breast cancers patients

171 aged between 20 and 60 (mean=44.04 years, $\mathrm{SD}=9.44$ ). The results confirmed thorough

172 coverage of the intended theoretical construct with the set of items included in this measure.

173 Furthermore, a pilot study (Chirico et al., 2012) revealed good internal consistency for this scale

174 (Cronbach's alpha $=0.75)$ on a sample of 100 newly-diagnosed breast cancer patients aged 26-

17574 years (mean $=45.22, \mathrm{SD}=9.27$ ). Participants from the pilot study and the present study were

176 both recruited from the same hospital, and in both instances, the measure was completed during

177 their hospitalization. Internal consistency reliability was comparable in the current

178 study (Cronbach's alpha $=0.72)$.

179 This measure was scored by calculating a mean score, with higher scores indicating more

180 positive patient attitudes towards breast cancer treatment.

181 Self-efficacy for behaviours related to coping with cancer. The Cancer Behaviour

182 Inventory (CBI, version-2) (Merluzzi et al., 2001) is a 33-item questionnaire that assesses self-

\footnotetext{
${ }^{1}$ In "think aloud" interviews the respondent is asked to think aloud as they answer questions thus verbalizing the thoughts that would normally remain silent during the process. Participants are not asked to explain or justify what they are doing and they are not asked to report their strategies. Thought processes are then examined for comprehension, recall and judgement difficulties. The methodology can be useful in identifying the face validity of the measure and any problematic questions (Drennan, 2003).
} 
183 efficacy for coping with cancer and includes the following scales: (a) maintenance of activity and

184 independence; (b) seeking and understanding medical information; (c) stress management; (d)

185 coping with treatment-related side-effects; (e) accepting cancer/maintaining positive attitude; (f)

186 affective regulation; and (g) seeking support. All items were rated on a nine-point Likert scale

187 ranging from 1 (not at all capable) to 9 (completely capable). As described in Table 2, all of the

188 sub-scales had an acceptable reliability (Cronbach's alpha ranging from 0.66 to 0.80 ) with the

189 exception of affective regulation (Cronbach's alpha $=0.42$ ), which was excluded from data

190 analysis. For each subscale item scores were averaged, thus higher scores indicated more self-

191 efficacy in each specific domains. A total self-efficacy score was also computed averaging these

192 subscales' mean scores.

193 Perceived social support. Perceived social support was measured by the

194 Multidimensional Scale of Perceived Social Support (MSPSS) (Zimet et al., 1990), a 12-item

195 questionnaire that measured the perceived adequacy of support given by three different sources:

196 family (four items), friends (four items), and significant other persons (four items). All items

197 were rated on a seven-point Likert scale ranging from 0 (strongly disagree) to 6 (strongly agree).

198 All the scales had good reliability (Cronbach's alpha $=0.89,0.91,0.91$, for family, friends and

199 other persons, respectively). For each subscale a mean score was calculated based on the item

200 scores, with higher scores indicating more perceived support. A total social support score was

201 also calculated by averaging the scores of each subscale.

202 Psychological distress. Anxiety was measured by the state form of the State-Trait

203 Anxiety Inventory (STAI Form Y; Spielberger, 1983). Items like "I feel nervous" were rated on

204 a four-point Likert scale ranging from 0 (almost never) to 3 (almost always). The scale showed a

205 good reliability based on the data in this study (Cronbach's alpha $=0.87$ ). Depression was 
206

207

208

209

210

211

212

213

214

215

216

217

measured by the CES-D scale (Radloff, 1977), a 20-item self-report scale designed to measure depressive symptoms in the general population but also used in cancer patients (van Wilgen et al., 2006). Participants were asked to indicate how often, over the past week, they experienced each of the 20 symptoms described in the CES-D scale. Responses were made on a four-point scale ranging from 0 (rarely or not at all) to 3 (most of or all the time). The scale had a good reliability (Cronbach's alpha $=0.88)$ based on the data in this study. Item scores for each measure (i.e., STAI \& CESD) were averaged to form an anxiety and a depression score with higher values indicating more anxiety and/or depression.

\section{Ethical considerations}

The ethics committee of the National Cancer Institute 'Giovanni Pascale' Foundation approved the study (n.29/11). Informed consent was obtained from all participants. Data were confidentially gathered and collected anonymously with a smart code used to refer to the case.

The voluntary nature of the study was emphasized and the authors have no conflicts of interest to report in the conduct of this study.

\section{Data analysis}

Preliminarily, we verified that none of the main key measures in the model was correlated with tumour stage or familial history of breast cancer. Furthermore, the bivariate correlations between all the key measures used in the study and their descriptive statistics were calculated and presented in Table 2 .

In order to test the hypothesized model, we used a Structural Equation Modelling (SEM) procedure. In particular we tested a mediational model, which hypothesized that age would be directly related knowledge that, in turn, would relate to attitudes and self-efficacy. Finally, the model also posed that these variables (i.e., attitudes and self-efficacy) and perceived social support 
229 would be directly related psychological distress. The direct and indirect effects of age and of 230 knowledge on psychological distress were also evaluated. Finally, the direct effects of age on other 231 variables (i.e. attitudes, self-efficacy, social support and psychological distress) were also 232 estimated in order control for the effects of age on the hypothesized relationships in the model. 233 The model's parameters were estimated using the Maximum Likelihood (ML) estimation 234 method through MPLUS-7 software (Muthen \& Muthen, 2012). In the tested model, both STAI 235 and CES-D scores were used as indicators of the latent variable representing psychological 236 distress; the three sub-scales of the MSPSS (i.e., family, friends and significant other person) 237 were indicators of the latent variable social support; and the knowledge scales scores (i.e., 238 knowledge about mammography, breast cancer, breast cancer treatment and early diagnosis of 239 breast cancer) were used as indicators of the latent variable knowledge. For the latent variable of 240 "self-efficacy", all the CBI subscales were considered as indicators with the exception of the 241 "affective regulation" and the "social support" subscales. The former was excluded for its low 242 reliability, the latter was excluded because the conceptual overlap and its high multicollinearity 243 with MSPSS scales (details of the full measurement model can be obtained from the first author 244 upon request). For the latent variable defined as "attitudes toward breast cancer treatment" an 245 item-parcelling procedure was used (Kim \& Hagtevt, 2003) in which the six items of the 246 attitudes scale were randomly grouped and averaged yielding three separate parcels, which 247 constituted three indicators of attitudes.

248 In order to evaluate the adequacy of the SEM analysis, we considered a variety of indices 249 of the degree of fit between input data and model-based estimates. The literature indicates the 250 following as good model-fit indices: TLI (Tucker-Lewis Index) or CFI (Comparative Fit Index) 251 values close to 0.95; RMSEA (Root Mean Square Error of Approximation) value below 0.06 (Hu 
$252 \&$ Bentler, 1999), a $\chi^{2} /$ df ratio below two (Tabachnick \& Fidell, 2007). Finally, in order to 253 analyze the indirect effects hypothesized, a SEM with a bias corrected (BC) bootstrap method 254 was used to establish confidence intervals (CIs) for the indirect effects and confirm their 255 statistical significance (Preacher \& Hayes, 2008). In particular in the present study, 95\% 256 confidence intervals were obtained with 1000 bootstrap resampling (Preacher \& Hayes, 2008).

\section{Results}

Table 2 contains the bivariate correlations between the variables in the study. More specifically, the correlations between key constructs are presented in bolded text (i.e., between psychological distress, perceived social support, self-efficacy, knowledge and attitudes). The age of the patients correlated significantly only with their knowledge $(r=-.18)$, which was correlated positively with attitudes $(r=.24)$ and self-efficacy $(r=.31)$; attitudes also correlated positively with social support $(r=.23)$ and with self-efficacy $(r=.38)$. The patients' knowledge $(r=-.22)$, attitudes $(r=-.22)$ and self-efficacy $(r=-.53)$ were negative correlated with distress. Finally social support correlated negatively with self-efficacy $(r=-.18)$.

As for the SEM analysis, which was performed to examine the mechanisms underlying and mediating the relationship between patients' age and psychological distress, the hypothesized model yielded very good fit indices $\left(\right.$ Chi-square $_{(106)}=122.115 ; \chi^{2} / \mathrm{df}=1.15 ; \mathrm{CFI}=$ $0.98, \operatorname{RMSEA}=0.034, \mathrm{SRMR}=0.058)$, in line with the criteria reported above. The measurement parameters of the model's latent constructs were statistically significant (all loadings $>0.51$ ).

271 Figure 1 shows the latent path estimations and latent covariance estimations.

273 knowledge ( $\beta=-0.22)$, which, in turn, was positively related to both attitudes toward breast cancer 274 treatment $(\beta=0.39)$ and coping self-efficacy $(\beta=0.36)$. Self-efficacy, in turn, represented the 
275 only variable of the hypothesized model that was directly and negatively related to patients' 276 psychological distress $(\beta=-0.68)$, which, contrary to hypothesis, is not significantly related to

277 either attitudes or social support. Finally, the analysis of the indirect effects of the hypothesized 278 model revealed a significant indirect effect of knowledge on psychological distress $(\beta=-.25$; BC 279 bootstrap CIs: from -.42 to -.08) through the mediation of the self-efficacy. Overall, the tested 280 model accounted for about $50 \%$ of the variance of the patients' psychological distress.

\section{Discussion}

The main aim of the present study was to gain a more thorough understanding of the

283

284

285

286

287

288

289

290

291

292

293

294

295

296

297

contribution of critical variables that determine individual differences in the level of

psychological distress experienced by newly diagnosed breast cancer patients before they begin treatment. Thus, variables that could exacerbate or lessen patients' psychological distress (e.g., Grassi et al., 1993; Merluzzi \& Sanchez, 1997; Merluzzi et al., 2001; Gilbar 2003; Mosher \& Danoff-Burg, 2005; Friedman et al., 2006; Arora et al., 2007; Henselmans et al., 2010; Heitzmann et al., 2011; Philip et al., 2013), were included in a model linking age, knowledge about breast cancer, attitudes toward cancer, coping efficacy, social support and distress outcomes. The findings of a SEM analysis substantially confirmed our hypothesized path model. First of all, age was related to patients' level of knowledge about breast cancer, specifically, older the patients had less knowledge about breast cancer and its treatment. This result is not consistent with those from other studies (e.g. Lukwago et al., 2003) and other populations (e.g., African Americans) suggesting that patients' knowledge could differently change with age as a function of the specific cultural context or at a latter phase in the treatment stage of cancer. In this study, older patients with lower knowledge, in turn, show lower scores in coping self-efficacy and a higher level of psychological distress. These results are in line with 
298 social cognitive theory (Bandura, 1997), which posits that patient's knowledge can directly relate

299 to self-efficacy. Finally, in the next phase of the model, our results confirmed past research

300 showing that self-efficacy mitigated psychological distress in cancer patients (e.g., Howsepian \&

301 Merluzzi, 2009; Heitzmann et al., 2011; Philip et al., 2013) and in particular in breast cancer

302 patients (Henselmans et al., 2010).

303 In contrast our younger patients showed more knowledge and positive attitudes toward

304 breast cancer treatment, perceived themselves as more efficacious in coping with their cancer

305 condition, and were less distressed. Thus, early on in the cancer trajectory, age can be considered

306 as a crucial precursor of patients' distress based mainly on deficits in knowledge, which then

307 leads to lack of confidence in coping efficacy and distress. This sequelae of effects could be

308 contrasted with past literature, which showed that younger age was related to greater distress

309 (e.g., van't Spijker et al., 1997; Avis et al., 2012; Mertz et al., 2012). However this could be

310 explained hypothesizing that the relationship between age and distress is strictly dependent by

311 the influence of a third variable, namely the level of knowledge, which is strictly dependent by

312 the cultural context. Consistently, some scholars (Grassi et al., 2015) suggested the need to take

313 into consideration the putative effects of variables that are strictly related to the cultural context

314 in which the study is performed. Thus, future research might contrast age and knowledge in

315 several different cultural contexts including Italy to determine if there are important cultural

316 differences in age and knowledge about breast cancer.

317 In our results the lack of a significant effect of social support on distress was unexpected.

318 Generally, the research on social support confirms its positive influence on outcomes such as

319 distress; however, its role may be related to where people are on the cancer trajectory. For example,

320 Philip et al. (2013) found that social support was not as important as coping self-efficacy for 
321 survivors. Perhaps this is also the case for patients who are post-diagnosis but pre-treatment. That

322 is, the patients in this study are at a point in the cancer trajectory where they may still rely on their

323 own coping efficacy and social support has not yet been engaged as a key variable in their

324 perceived ability to cope with the disease. As they progress into active treatment (surgery and

325 adjuvant chemotherapy) the role of social support may emerge as a critical component of the

326 coping process.

327 There were also a no significant direct effects of attitudes on patients' distress, but there

328 is a negative bivariate correlation between the two. Furthermore there is a positive relationship

329 between attitudes and self-efficacy. These results suggest that attitudes may be operating through

330 self-efficacy to augment the mitigation of distress. It is likely that, because attitudes are able to

331 directly predict volitional and goal oriented health behaviors, they are less related to mood state

332 (i.e., Manning \& Bettencourt, 2011) than to agency, which is reflected in its relationship with

333 coping efficacy.

334 The abatement of distress early in the diagnosis and treatment of cancer may have long-

335 term beneficial effects. In her bio-behavioral model (Andersen et al., 2009), Andersen, stated that

336 an important sequela of distress is (non)compliance. Many studies have shown a positive

337 association between distress and decreased acceptance of and compliance with treatment (Ayres

338 et al., 1994; Colleoni et al., 2000; Bui et al., 2005), which may, in turn, affect disease outcomes,

339 the prevention of recurrence, and long-term survivorship. Knowing some of the risk factors that

340 were present in this study may help guide a process of early intervention to avoid the

341 exacerbation of distress. According to our findings, it might be crucial for interventions to focus

342 on patients' beliefs and knowledge about breast cancer and its treatment. In fact, according to our

343 findings and other scholars' suggestions (Heitzmann et al., 2011; Yi \& Park, 2012), an increase 
344 in patients' knowledge about cancer, its detection, and its treatment can directly improve self-

345 efficacy to cope with several aspects of their illness and, indirectly, their psychological distress

346 (Chen et al., 2008). In addition, there are several studies that have recently investigated the

347 effects of psychosocial interventions that enhance self-efficacy, showing a reduction of patients'

348 psychological distress for both professionally run programs (e.g., Abernethy et al., 2010; Smith

349 et al., 2011) as well as those conducted by trained breast cancer survivors (Yi \& Park, 2012).

350 The use of a cross-sectional design is one of the limitations of the present study; thus,

351 future studies should explore some of the same issues but in a longitudinal design. Furthermore,

352 it is important to reiterate that our findings stemmed from a sample of newly diagnosed patients.

353 Future studies might explore the social cognitive mediation model proposed in the present

354 investigation to account for possible indicators of psychological distress in patients at different

355 stages of their illness and its treatment. Finally, as mentioned previously, some specific findings

356 (i.e., the relationship between age and patients' knowledge) might be related to the specific

357 cultural context in which the study was performed; thus, the comparative culturally-based study

358 of processes early in the cancer trajectory would help determine those aspects that are universal

359 and those that have more cultural specificity.

360

\section{Conclusion}

361 The findings of the present research have direct, practical implications for healthcare

362 professionals who work with breast cancer patients. They can play a crucial role in assessing and

363 imparting correct knowledge about breast cancer and its treatment shortly after diagnosis. In fact,

364 consistent with our findings, increasing patients' knowledge about breast cancer could directly

365 improve their self-efficacy to cope with cancer and psychological distress. 
368

369

370

371

372

373

374

375

376

377

378

379

380

381

382

383

384

385

386

387

388

Abernethy AP, Herndon Ii JE, Coan A, Staley T, Wheeler JL, Rowe K, Smith SK, Lyerly HK. 2010. Phase 2 pilot study of pathfinders: A psychosocial intervention for cancer patients. Supportive Care in Cancer 18(7): 893-898.

Ajzen I. 1991. The theory of planned behavior. Organizational Behavior and Human Decision Processes 50(2): 179-211.

Alm-Roijer C, Fridlund B, Stagmo M, Erhardt L. 2006. Knowing your risk factors for coronary heart disease improves adherence to advice on lifestyle changes and medication. Journal of Cardiovascolar Nursing 21: E24-E31.

Alm-Roijer C, Stagmo M, Uden G, Erhardt L. 2004. Better knowledge improves adherence to lifestyle changes and medication in patients with coronary heart disease.European Journal of Cardiovascular Nursing 3: 321-330.

Andersen BL, Kiecolt-Glaser JK, Glaser R. 1994. A biobehavioral model of cancer stress and disease course. American Psychologist 49(5):389-404.

Andersen BL, Yang HC, Farrar WB, Golden-Kreutz DM, Emery CF, Thornton LM, Young DC, Carson WE 3rd. 2008. Psychologic intervention improves survival for breast cancer patients: a randomized clinical trial. Cancer. 113(12):3450-8. doi: 10.1002/cncr.23969.

Andreu Y, Galdón MJ, Durá E, Martínez P, Pérez S, Murgui S. 2012. A longitudinal study of psychosocial distress in breast cancer: Prevalence and risk factors. Psychology \& Health 27(1): $72-87$.

Andrykowski MA, Cordova MJ, Studts JL, Miller TW. 1998. Posttraumatic stress disorder after treatment for breast cancer: Prevalence of diagnosis and use of the PTSD Checklist - Civilian 
Version (PCL-C) as a screening instrument. Journal of Consulting and Clinical Psychology 66(3): 586-590.

391

Arora NK, Finney Rutten LJ, Gustafson DH, Moser R, Hawkins RP. 2007. Perceived helpfulness and impact of social support provided by family, friends, and health care providers to women newly diagnosed with breast cancer. Psycho-Oncology 16(5): 474-486. DOI:

$$
\text { 10.1002/pon. } 1084
$$

Avci IA. 2008. Factors associated with breast self-examination practices and beliefs in female workers at a Muslim community. European Journal of Oncology Nursing 12 (2): 127-133.

Avis NE, Crawford S, Manuel J. 2005. Quality of life among younger women with breast cancer. Journal of Clinical Oncology 23(15): 3322-3330.

Avis NE, Levine B, Naughton MJ, Case DL, Naftalis E, Van Zee KJ. 2012. Explaining agerelated differences in depression following breast cancer diagnosis and treatment. Breast Cancer Research and Treatment 136 (2): 581-591.

Ayres A, Hoon PW, Franzoni JB, Matheny KB, Cotanch PH, Takayanagi S. 1994. Influence of mood and adjustment to cancer on compliance with chemotherapy among breast cancer patients; Journal of Psychosomatic Research 38: 393-402

Badger TA, Braden CJ, Mishel MH, Longman A. 2004. Depression burden, psychological adjustment, and quality of life in women with breast cancer: patterns over time. Research in Nursing and Health 27(1):19-28..

Bandura A. 1991. Social cognitive theory of self-regulation. Behavior and Human Decision Processes 50 (2): 248-287.

Bandura A. 1997. Self-efficacy: The Exercise of Control. Cambridge University Press: New York, US. 
412 Bandura A, Pastorelli C, Barbaranelli C, Caprara GV. 1999. Self-efficacy pathways to childhood 413 depression. Journal of Personality and Social Psychology 76 (2): 258-269.

414 Bárez M, Blasco T, Fernández-Castro J, Viladrich C. 2007. A Structural Model of the

415 Relationships Between Perceived Control and Adaptation to Illness in Women with Breast 416 Cancer. Journal of Psychosocial Oncology 25(1): 21-43.

417 Bui QU, Ostir GV, Kuo YF, Freeman J, Goodwin JS. 2005. Relationship of depression to patient 418 satisfaction: findings from the barriers to breast cancer study; Breast Cancer Research and 419 Treatment 89: $23-28$

420 Burgess C, Cornelius V, Love S, Graham J, Richards M, Ramirez A. 2005. Depression and 421 anxiety in women with early breast cancer: five year observational cohort study. British $422 \quad$ Medical Journal 330: 402-705.

423 Butler L, Downe-Wamboldt B, Melanson P, Coulter L, Keefe J, Singleton J, Bell D. 2006.

424 Prevalence, correlates and costs of patients with poor adjustment to mixed cancers. Cancer $425 \quad$ Nursing 29: 9-16.

426 Carver C, Pozo C, Harris S, Noriega V, Scheier MF, Robinson DS, Ketcham AS, Moffat FL Jr, 427 Clark KC. (1993). How coping mediates the effects of optimism on distress: A study of 428 women with early stage breast cancer. Journal of Personality and Social Psychology 65(2): 429 375-390. Doi: 10.1037/0022-3514.65.2.375

430 Carver CS, Scheier MF. 2000. Scaling back goals and recalibration of the affect system are 431 processes in normal adaptive self-regulation: understanding 'response shift' phenomena. $432 \quad$ Social Science and Medicine 50(12):1715-22. 
433 Chen JY, Diamant AL, Thind A, Maly RC. 2008. Determinants of breast cancer knowledge

434 among newly diagnosed, low-income, medically underserved women with breast cancer.

435 Cancer 112: 1153-1161. doi: 10.1002/cncr.23262

436 Chirico, A., Lucidi, F., Mallia, L., D’Aiuto, M, D’Aiuto, G. (2012). La reazione di fronte a una

437 diagnosi di breast cancer: aspetti socio-cognitivi associati alle differenze individuali nei

438 livelli di distress psicologico. Poster session presented at the meeting of Associazione

439 Italiana di Psicologia-Congresso Nazionale delle Sezioni. Chieti, Italy 20-23 September.

440 Colleoni M, Mandala M, Peruzzotti G, Robertson C, Bredart A, Goldhirsch A. 2000. Depression

441 and degree of acceptance of adjuvant cytotoxic drugs. Lancet 356: 1326-1327

442 Costa-Requena G, Rodríguez A, Fernández-Ortega P. 2013. Longitudinal assessment of distress

443 and quality of life in the early stages of breast cancer treatment Scandinavian Journal of

$444 \quad$ Caring Sciences 27 (1): 77-83.

445 Costanzo ES, Lutgendorf SK, Mattes ML, Trehan S, Robinson CB, Tewfik F, Roman SL. 2007

446 Adjusting to life after treatment: distress and quality of life following treatment for breast

447 cancer. Breast Journal of Cancer 97(12):1625-31.

448 Deshields D, Tibbs T, Fan MY, Taylor M. 2006. Differences in patterns of depression after

449 treatment for breast cancer. Psycho-Oncology 15: 398-406.

450 Drageset S, Lindstrøm TC, Giske T, Underlid K. 2012. "The support I need": Women's

451 experiences of social support after having received breast cancer diagnosis and awaiting

$452 \quad$ surgery. Cancer Nursing 35 (6): E39-E47.

453 Drennan, J. (2003). Cognitive interviewing: verbal data in the design and pre-testing of

454 questionnaires. Journal of Advanced Nursing 42: 57-63 
455 Fiszer C, Dolbeault S, Sultan S, Brédart A. 2014. Prevalence, intensity, and predictors of the 456 supportive care needs of women diagnosed with breast cancer: a systematic review. 457 Psychooncology 23(4): 361-74. doi: 10.1002/pon.3432.

458 Friedman LC, Kalidas M, Elledge R, Chang J, Romero C, Husain I, Dulay MF, Liscum KR. 459 2006. Optimism, social support and psychosocial functioning among women with breast $460 \quad$ cancer. Psycho-Oncology 15(7): 595-560.

461 Gallagher J, Parle M, Cairns D. 2002. Appraisal and psychological distress six months after 462 diagnosis of breast cancer. Breast Journal of Health Psychology 7(Part 3):365-376.

463 Gilbar O. 2003. Do Attitudes Toward Cancer, Sense of Coherence and Family High Risk Predict 464 More Psychological Distress in Women Referred for a Breast Cancer Examination? Women 465 Health 38(2): 35-46.

466 Grassi L, Rosti G, Lasalvia A, Marangolo M. 1993. Psychosocial variables associated with 467 mental adjustment to cancer. Psycho-Oncology 2: 11-20.

468 Grassi L, Caruso R, Sabato S, Massarenti S, Nanni MG, UniFe PWGC. 2015. Psychosocial 469 screening and assessment in oncology and palliative care settings. Frontiers in Psychology $470 \quad 1485: 1-6$.

471 Greenfield S, Kaplan S, Ware JE Jr. 1985. Expanding patient involvement in care. Effects on 472 patient outcomes. Annals of Internal Medicine 102: 520-528.

473 Kim S \& Hagtevt KA. 2003. The impact of misspecified item parceling on representing latent 474 variables in covariance structure modelling: a simulation study. Structural Equation $475 \quad$ Modeling 10: 101-27. 
476 Heisler M, Bouknight RR, Hayward RA, Smith DM, Kerr EA 2002. The relative importance of 477 physician communication, participatory decision making, and patient understanding in 478 diabetes self-management. Journal of General Internal Medicine 17: 243-252.

479 Heitzmann CA, Merluzzi TV, Jean-Pierre P, Roscoe J, Kirsh K, Passik SD. 2011. Assessing self480 efficacy for coping with cancer: Development and psychometric analysis of the brief version 481 of the Cancer Behavior Inventory (CBI-B). Psycho-Oncology 20(3): 302-312.

482 Henselmans I, Fleer J, de Vries J, Baas PC, Sanderman R, Ranchor AV. 2010. The adaptive 483 effect of personal control when facing breast cancer: Cognitive and behavioural mediators. $484 \quad$ Psychology and Health 25(9): 1023-1040.

485 Hill J, Holcombe C, Clark L, Boothby MRK, Hincks A, Fisher J, Tufail S, Salmon P. 2011. 486 Predictors of onset of depression and anxiety in the year after diagnosis of breast cancer. $487 \quad$ Psychological Medicine 41: 1429-1436.

488 Holt CL, Clark EM, Kreuter MW, Rubio DM. 2003a. Spiritual Health Locus of Control and 489 Breast Cancer Beliefs Among among low-income Urban African American Women. Health $490 \quad$ Psychology 22: 294-299.

491 Holt CL, Lukwago SN, Kreuter MW. 2003b. Spirituality, breast Cancer beliefs and 492 mammography utilization among Urban African American women. Journal of Health $493 \quad$ Psychology 8(3): 383-396.

494 Howsepian BA \& Merluzzi TV. 2009. Religious beliefs, social support, self-efficacy and 495 adjustment to cancer. Psycho-Oncology 18(10): 1069-1079.

496 Hu LT \& Bentler PM. 1999. Cutoff Criteria for Fit Indexes in Covariance Structure Analysis:

497 Conventional Criteria Versus New Alternatives. Structural Equation Modeling 6: 1-55. 
498 Ievers CE, Brown RT, Drotar D, Caplan D, Pishevar BS, Lambert RG. 1999. Knowledge of 499 physician prescriptions and adherence to treatment among children with cystic fibrosis and 500 their mothers. Journal of Developmental \& Behavioral Pediatrics 20: 335-343.

501 Iwatani T, Matsuda A, Kawabata H, Miura D, Matsushima E. 2013. Predictive factors for 502 psychological distress related to diagnosis of breast cancer. Psycho-Oncology 22(3): 523$503 \quad 529$.

504 Johnson K, Chang M, Sun Y, Miyake M, Rosser C. 2013. Attitudes and knowledge of primary 505 care physicians regarding prostate cancer. Journal of Cancer Education 28: 679-683.

506 Lam WW, Chan M, Ka HW, Fielding R. 2007. Treatment decision difficulties and post-operative 507 distress predict persistence of psychological morbidity in Chinese women following breast 508 cancer surgery. Psychooncology 16(10): 904-12.

509 Lam WW, Shing YT, Bonanno GA, Mancini AD, Fielding R. 2012 Distress trajectories at the 510 first year diagnosis of breast cancer in relation to 6 years survivorship. Psychooncology $51121(1): 90-9$. doi: 10.1002/pon.1876.

512 Lauzier S, Maunsell E, Levesque P, Mondor M, Robert J, Robidoux A., Provencher L. 2010.

513 Psychological distress and physical health in the year after diagnosis of DCIS or invasive breast 514 cancer. Breast Cancer Research and Treatment 120: 685-691.

515 Lepore S, \& Coyne J. 2006. Psychological interventions for distress in cancer patients: A review 516 of reviews. Annals of Behavioral Medicine 32: 85-92.

517 Lukwago SN, Kreuter MW, Holt CL, Steger-May K, Bucholtz DC, Skinner CS. 2003. Socio-

518 cultural correlates of breast cancer knowledge and screening in urban African-American 519 women. American Journal of Public Health 93: 1271-1274. 
520 Manning M \& Bettencourt BA. 2011. Depression and medication adherence among breast cancer

521 survivors: Bridging the gap with the theory of planned behavior. Psychology \& Health 26(9):

$522 \quad 1173-1187$.

523 Maunsell E, Brisson J, Deschi'nes L. 1992. Psychological Distress After Initial Treatment of

524 Breast Cancer Assessment of Potential Risk Factors. Cancer 70(1): 120-125.

525 Mehnert A \& Koch U. 2008. Psychological co-morbidity and health-related quality of life and its 526 association with awareness, utilization and need for psychosocial support in a cancer register 527 based sample of long-term breast cancer survivors. Journal of Psychosomatic Research 64:

$528 \quad 383-39$.

529 Merluzzi TV \& Sanchez MAM. 1997. Assessment of self-efficacy and coping with cancer:

530 development and validation of cancer behavior inventory. Health Psychology 16(2): 163-170.

531 Merluzzi TV, Nairn RC, Hegde K, Sanchez MAM, Dunn L. 2001. Self-Efficacy For Coping

532 With Cancer: Revision Of The Cancer Behavior Inventory (Version 2.0). Psycho-Oncology 533 10: 206-217.

534 Mertz BG, Bistrup PE, Johansen C, Dalton SO, Deltour I, Kehlet H, Kroman N. 2012.

535 Psychological distress among women with newly diagnosed breast cancer. European Journal 536 of Oncology Nursing 16 (4): 439-443.

537 Millar K, Purushotham AD, McLatchie E, George WD, Murray GD. 2005. A 1-year prospective 538 study of individual variation in distress, and illness perceptions, after treatment for breast 539 cancer. Journal Psychosomatic Research 58(4): 335-42.

540 Miller LG, Liu H, Hays RD, Golin CE, Ye Z, Beck CK, Kaplan AH, Wenger NS.

541 2003. Knowledge of antiretroviral regimen dosing and adherence: a longitudinal study. Clinical 542 Infectious Disease 36: 514-518. 
543 Montgomery M. \& McCrone SH. 2010. Psychological distress associated with the diagnostic

544 phase for suspected breast cancer: systematic review. Journal of Advanced Nursing 66(11):

$545 \quad 2372-2390$.

546 Mosher CE \& Danoff-Burg S. 2005. A Review of Age Differences in Psychological Adjustment 547 to Breast Cancer. Journal of Psychosocial Oncology 23: 101-114.

548 Muthen LK. \& Muthen BO. 2012. Mplus User's Guide. Seventh Edition. Muthen \& Muthen: Los $549 \quad$ Angeles.

550 Nausheen B, Gidron Y, Peveler R, Moss R. 2009. Social support and cancer progression: a 551 systematic review. Journal of Psychosomatic Research 67: 403-1

552 Nosarti C, Roberts J, Crayford T, McKenzie K, David A. 2001. Early psychological adjustment 553 in breast cancer patients. A prospective study. Journal of Psychosomatic Research 53:1123$554 \quad 1130$.

555 Ohaeri BM, Ofi AB, Campbell OB. 2012. Relationship of knowledge of psychosocial issues 556 about cancer with psychic distress and adjustment among breast cancer clinic attendees in a $557 \quad$ Nigerian teaching hospital. Psycho-Oncology 21(4): 419-426.

558 Philip EJ, Merluzzi TV, Zhang Z, Heitzmann CA. 2013. Depression and cancer survivorship: 559 importance of coping self-efficacy in post-treatment survivors. Psycho-Oncology 22: 987560994.

561 Piscitelli P, Santoriello A, Buonaguro FM, Di Maio M, Iolascon G, Gimigliano F. Marinelli A,

562 Distante A, Serravezza G, Sordi E, Cagossi K, Artioli F, Santangelo M, Fucito A, Gimigliano

563 R, Brandi ML, Crespi M, Giordano A; CROM; Human Health Foundation Study Group. 564 2009. Incidence of breast cancer in Italy: mastectomies and quadrantectomies performed 

between 2000 and 2005. Journal of Experimental \& Clinical Cancer Research 28(1): 86 DOI:10.1186/1756-9966-28-86

567 Preacher KJ \& Hayes AF. 2008. Asymptotic and resampling strategies for assessing and comparing indirect effects in multiple mediator models. Behavior Research Methods 40(3):

Radloff LS. 1977. The CES-D Scale: A Self-Report Depression Scale for Research in the General Population. Applied Psychological Measurement: 1, 385-401.

572

573

Reich M, Lesur A, Perdrizet-Chevallier C. 2008. Depression, quality of life and breast cancer: a review of the literature. Breast Cancer Research and Treatment 110: 9-17.

Roberts KJ. 2000. Barriers to and facilitators of HIV-positive patients' adherence to antiretroviral treatment regimens. AIDS Patient Care STDS 14: 155-168.

Schernhammer E, Haidinger G, Waldhör T, Vargas R, Vutuc C. 2010. A Study of trends in beliefs and Attitudes Toward Cancer. Journal of Cancer Education 25: 211-216.

Schoenfeld ER, Greene JM, Wu SY, Leske MC. 2001. Patterns of adherence to diabetes vision care guidelines: baseline findings from the Diabetic Retinopathy Awareness Program. Ophthalmology 108: 563-571.

Smith SK, Herndon JE, Lyerly HK, Coan A, Wheeler JL, Staley T, Abernethy AP. 2011. Correlates of quality of life-related outcomes in breast cancer patients participating in the Pathfinders pilot study. Psycho-Oncology 20(5): 559-564.

Spielberger CD. 1983. Manual for the State-Trait Anxiety Inventory. Consulting Psychologists Press: Palo Alto, CA. 
586 Stanton AL, Danoff-Burg S, Cameron CL, Bishop M, Collins CA, Kirk SB, Sworowski LA,

587 Twillman R. 2000. Emotionally expressive coping predicts psychological and physical

588 adjustment to breast cancer. Journal of Consulting and Clinical Psychology 68(5): 875-82.

589 Tabachnick BG \& Fidell LS. 2007 Using Multivariate Statistics (5th edition). Allyn and Bacon:

$590 \quad$ New York.

591 Tang EO, Lai CS, Lee KK, Wong RS, Cheng G, Chan TY. 2003. Relationship between patients'

592 warfarin knowledge and anticoagulation control. Ann Pharmacother 37: 34-39.

593 Vahdaninia M, Omidvari S, Montazeri A. 2010. What do predict anxiety and depression in breast

594 cancer patients? A follow-up study. Social Psychiatry and Psychiatric Epidemiology 45: 355$595 \quad 361$.

596 van't Spijker A, Trijsburg RW, Duivenvoorden HJ. 1997. Psychological sequel of cancer

597 diagnosis: A meta-analytical review of 58 studies after 1980. Psychosomatic Medicine 59(3):

$598 \quad 280-293$.

599 van Wilgen CP, Dijkstra PU, Stewart RE, Ranchor AV, Roodenburg JLN. 2006. Measuring

600 Somatic Symptoms With the CES-D to Assess Depression in Cancer Patients After

601 Treatment: Comparison Among Patients With Oral/Oropharyngeal, Gynecological,

602 Colorectal, and Breast Cancer. Psychosomatics 47: 465- 470.

603 Yi M. \& Park EY. 2012. Effects of breast health education conducted by trained breast cancer

604 survivors. Journal of Advanced Nursing 68 (5): 1100-1110.

605 Zabora J, Brintzenhofe SK, Curbow B, Hooker C, Piantadosi S. 2001. The prevalence of

606 psychological distress by cancer site. Psycho-Oncology 10:19-28. 
607 Zimet G, Powell S, Farley GK, Werkman S, Berkoff KA. 1990. Psychometric Characteristics of 608 the Multidimensional Scale of Perceived Social Support. Journal of Personality Assessment $609 \quad 55: 610-617$.

610 


\section{Table $\mathbf{1}$ (on next page) \\ description of the sample}


2 Table 1. Description of the sample

\begin{tabular}{lr}
\hline Age Distribution in percentiles \\
25th \\
50th & $39,00 \mathrm{yrs}$ \\
75th & $45,00 \mathrm{yrs}$ \\
Breast Cancer Stage & $52,00 \mathrm{yrs}$ \\
T1 & \\
T2 & $55,9 \%$ \\
T3 & $20,5 \%$ \\
T4 & $14,2 \%$ \\
Familiar History of Breast Cancer & $9,4 \%$ \\
Surgical Treatment & $32,8 \%$ \\
$\quad$ Lumpectomy & $26,0 \%$ \\
$\quad$ Quadrantectomy with LNS & $51,2 \%$ \\
$\quad$ Mastectomy & $22,8 \%$ \\
\hline
\end{tabular}


Table 2 (on next page)

Correlation matrix, descriptive statistics and reliability of the key variables of the study Note: All the correlation coefficients are statistically significant at least at a p-level of .05, with the exception of underlined coefficients. In bold are reported the correlation between the main key variables of the study. 
2 Table 2. Correlation matrix, descriptive statistics and reliability of the key variables of the study

\begin{tabular}{|c|c|c|c|c|c|c|c|c|c|c|c|c|c|c|c|c|c|c|c|c|}
\hline & 1 & 2 & 2.1 & 2.2 & 3 & 3.1 & 3.2 & 3.3 & 4 & 4.1 & 4.2 & 4.3 & 4.4 & 4.5 & 4.6 & 4.7 & 5 & 5.1 & 5.2 & 5.3 \\
\hline 1. Age & - & & & & & & & & & & & & & & & & & & & \\
\hline 2. Psychological distress & $\underline{-.10}$ & - & & & & & & & & & & & & & & & & & & \\
\hline 2.1 Anxiety (STAI mean score) & .12 & .91 & - & . & & & & & & & & & & & & & & & & \\
\hline 2. 2Depressive (CES-D mean score) & .06 & .92 & .69 & - & & & & & & & & & & & & & & & & \\
\hline 3 Perceived Social Support & $\underline{-.05}$ & $\underline{-.13}$ & $\underline{-.10}$ & $\underline{-.13}$ & - & & & & & & & & & & & & & & & \\
\hline 3.1 Family perceived support & $\underline{-.04}$ & $\underline{-.06}$ & $\underline{-.05}$ & $\underline{-.06}$ & .86 & - & & & & & & & & & & & & & & \\
\hline 3.2 Friends perceived support & .00 & $\underline{-.08}$ & $\underline{-.05}$ & $\underline{-.08}$ & .81 & .54 & - & & & & & & & & & & & & & \\
\hline 3.3 Significant other persons perceived support & $\underline{-.11}$ & -.18 & $\underline{-.15}$ & -18 & .82 & .62 & .43 & - & & & & & & & & & & & & \\
\hline 4. Self-efficacy & $\underline{-.13}$ & -.53 & -.48 & -.51 & -.18 & .05 & .10 & .29 & - & & & & & & & & & & & \\
\hline 4.1 Maintenance of activity and independence & $\underline{-.09}$ & -.34 & -.33 & -.31 & .06 & $\underline{-.02}$ & .02 & .15 & .69 & - & & & & & & & & & & \\
\hline 4.2 Seeking and understanding medical information & $\underline{-.09}$ & -.26 & -.26 & -.23 & .12 & .02 & .07 & .20 & .69 & .39 & - & & & & & & & & & \\
\hline 4.3 Stress management & $\underline{-.13}$ & -.60 & -.56 & -.56 & .11 & .03 & .04 & .22 & .80 & .47 & .47 & - & & & & & & & & \\
\hline 4.4 Coping with treatment- related side effects & $\underline{-.07}$ & -.47 & -.43 & -.45 & .02 & $\underline{-.06}$ & .01 & .11 & .79 & .40 & .44 & .68 & - & & & & & & & \\
\hline 4.5. Accepting cancer/maintaining positive attitude & $\underline{-.09}$ & -.55 & -.50 & -.52 & .09 & .03 & $\underline{-.04}$ & .24 & .82 & .62 & .40 & .70 & .66 & - & & & & & & \\
\hline 4.6. Affective regulation & $\underline{-.01}$ & -.19 & $\underline{-.16}$ & -.19 & .14 & .07 & .13 & .16 & .62 & .36 & .43 & .32 & .37 & .40 & - & & & & & \\
\hline 4.7 Seeking social support & $\underline{-.14}$ & -.26 & $\underline{-.17}$ & -.30 & .34 & .19 & .28 & .37 & .69 & .43 & .39 & .41 & .39 & .44 & .46 & - & & & & \\
\hline 5. Patients' Knowledge & -.18 & -.22 & -.20 & -.21 & .07 & $\underline{-.04}$ & .13 & .08 & .31 & .17 & .23 & .23 & .28 & .22 & .12 & .28 & - & & & \\
\hline 5.1 Mammography knowledge & $\underline{-.10}$ & $\underline{-.11}$ & $\underline{-.10}$ & $\underline{-.11}$ & .07 & .05 & .03 & .11 & .23 & .18 & .14 & .12 & .25 & .25 & $\underline{-.01}$ & .20 & .76 & - & & \\
\hline 5.2 Breast cancer knowledge & $\underline{-.17}$ & -.20 & -.18 & -.19 & .04 & $\underline{-.06}$ & .10 & .05 & .21 & .10 & .22 & .16 & .15 & .12 & .14 & .18 & .78 & .30 & - & \\
\hline 5.3 Breast cancer treatment knowledge & $\underline{-.11}$ & -.18 & $\underline{-.16}$ & $\underline{-.17}$ & .04 & $\underline{-.09}$ & .18 & $\underline{-.01}$ & .24 & .07 & .14 & .26 & .22 & .08 & .15 & .26 & .64 & .33 & .30 & - \\
\hline 6. Attitudes towards breast cancer treatment & $\underline{-.09}$ & -.22 & $\underline{-.17}$ & -.23 & .23 & $\underline{.13}$ & .19 & .26 & .38 & .20 & .34 & .28 & .29 & .27 & .21 & .34 & .24 & .10 & .19 & .27 \\
\hline Mean & 45.69 & 1.2 & 1.25 & 1.27 & 4.43 & 4.56 & 4.00 & 4.68 & 5.91 & 6.89 & 6.67 & 5.59 & 4.34 & 6.09 & 5.85 & 5.78 & 2.40 & 2.72 & 2.36 & 2.06 \\
\hline SD & 10.01 & .46 & .47 & .54 & 1.11 & 1.28 & 1.45 & 1.32 & 1.28 & 1.46 & 1.82 & 1.88 & 2.10 & 1.64 & 1.27 & 2.00 & .86 & 1.27 & 1.41 & .82 \\
\hline Cronbach's alpha & & & .87 & .88 & & .89 & .91 & .91 & & .78 & .68 & .70 & .80 & .76 & .42 & .66 & & & & \\
\hline
\end{tabular}

3 Note: All the correlation coefficients are statistically significant at least at a p-level of .05, with the exception of underlined coefficients. In

4 bold are reported the correlation between the main key variables of the study. 


\section{PeerJ Reviewing Manuscript}


1

Model

Hypothesized model with estimation path. Path significant at $p<0.05$

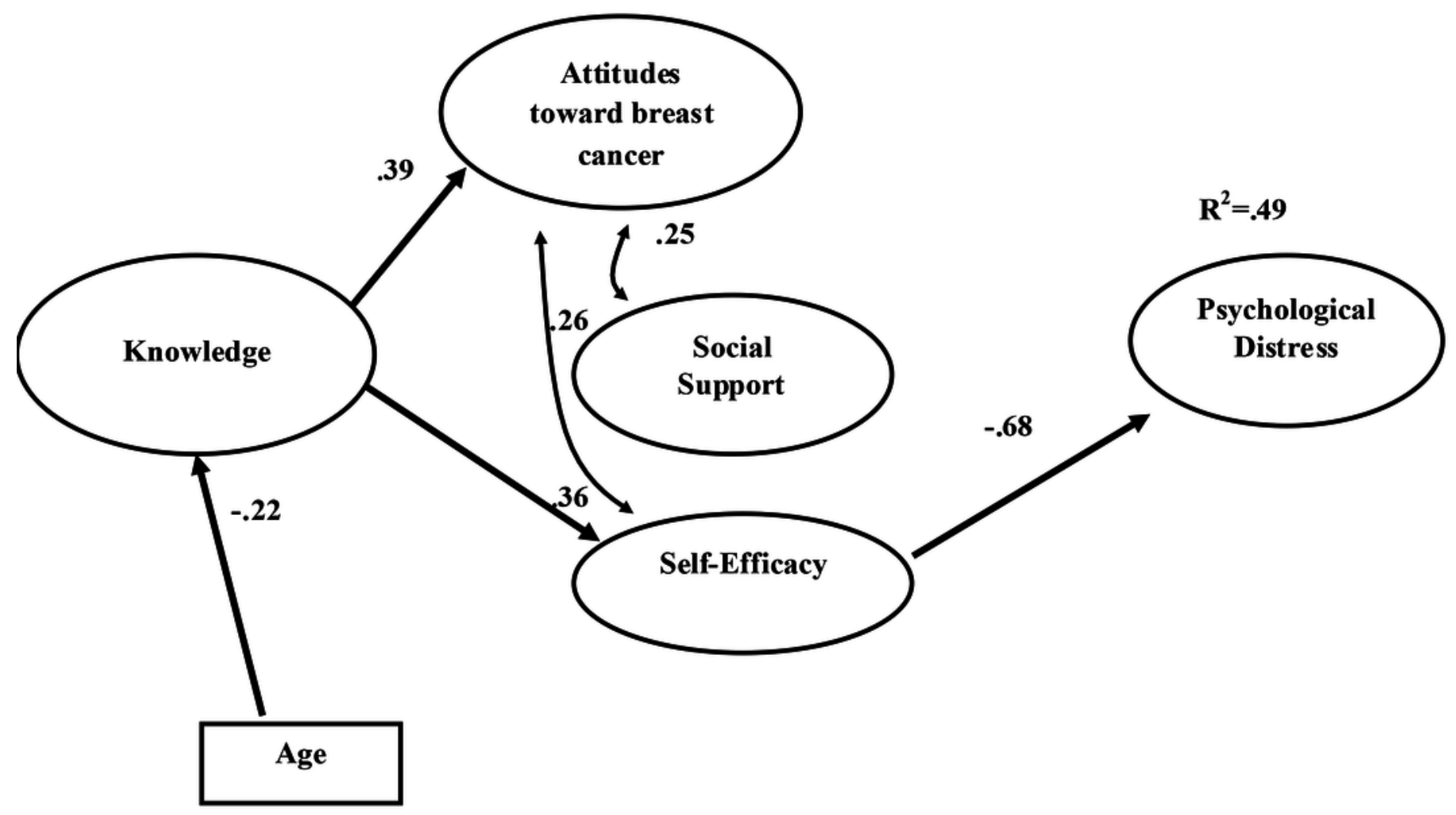

Paths significant at $\mathrm{p}<0.05$ 